\title{
Migration of regulatory $\mathbf{T}$ cells toward airway epithelial cells is impaired in chronic rhinosinusitis with nasal polyposis
}

\author{
Yong Min Kim ${ }^{\mathrm{a}, \mathrm{b}, \mathrm{c}}$, Amanda Munoz ${ }^{\mathrm{b}}$, Peter H. Hwang ${ }^{\mathrm{b}, 1}$, and Kari C. Nadeau ${ }^{\mathrm{c},}{ }^{*}, 1$ \\ aDepartment of Otolaryngology-Head and Neck Surgery, Chungnam National University, School \\ of Medicine, Daejeon, Korea \\ bepartment of Otolaryngology-Head and Neck Surgery, Stanford University, School of Medicine, \\ Stanford, CA, USA \\ 'Division of Immunology and Allergy, Stanford University, School of Medicine, Stanford, CA, USA
}

\section{Abstract}

The pathogenesis of chronic rhinosinusitis with nasal polyposis (CRSwNP) is still unclear. To evaluate the role of regulatory $\mathrm{T}$ cells (Treg) in the pathogenesis of nasal polyposis, we tested migration potential of Treg purified from subjects with CRSwNP, CRS without NP and controls. The nasal tissue expressions of FOXP3 were analyzed by means of RT-PCR and double immunohistochemistry. Chemotaxis assays were used to evaluate the migration potential of Treg onto bronchial epithelial cells and primary nasal epithelial cells, and toward chemokines. FOXP $3^{+} \mathrm{CD}^{+}$cells frequency and FOXP3 transcript expression in nasal tissue, and migration potentials of Treg toward airway epithelial cells and CCL1 were significantly lower in CRSwNP compared with other groups $(P<0.05)$. These results indicate that migration potential of Treg is decreased in CRSwNP subjects, and this may be one of the reasons why tissue infiltration of Treg was decreased as seen in the immunohistochemistry of nasal polyps from CRSwNP subjects.

\section{Keywords}

Chronic rhinosinusitis; Nasal polyp; T regulatory cells; FOXP3; Chemotaxis

\section{Introduction}

Chronic rhinosinusitis with nasal polyposis (CRSwNP) and without nasal polyposis (CRSsNP) are chronic and persistent inflammatory diseases of the nasal and paranasal sinus mucosa. CRSsNP is associated with a predominant $\mathrm{T}_{\mathrm{H}} 1$ polarization, whereas CRSwNP is typically characterized by $\mathrm{T}_{\mathrm{H}} 2$ skewed eosinophilic inflammation [1]. Although insights into the pathophysiology of CRS have largely expanded over the last two decades, further details on the etiology and pathogenesis need to be understood.

\footnotetext{
(C) 2010 Elsevier Inc. All rights reserved.

*Corresponding author. Allergy Clinics, Division of Allergy and Immunology, Stanford University, Stanford, CA 94305-5208, USA. Fax: +1 6504985560 .

${ }^{1}$ These authors contributed equally to this work.
} 
A number of recent studies indicate that $\mathrm{CD} 4^{+} \mathrm{CD} 25^{\mathrm{hi}} \mathrm{CD} 127^{\mathrm{lo} /-}$ regulatory $\mathrm{T}$ cells (Treg) play an important role in diseases characterized by $\mathrm{T}_{\mathrm{H}}$ 2-biased immune responses such as asthma and atopic dermatitis [2-4]. Treg are chiefly involved in peripheral tolerance and are also important for normal immune homeostasis in the airway [5]. They can migrate to sites of inflammation and suppress immune responses via direct cell-cell contact, as well as secretion of TGF- $\beta$ and IL-10 [6].

Forkhead box P3 (FOXP3) is specifically expressed by Treg and programs their development and function $[7,8]$. Recent studies have reported a selective decrease in the frequency of regulatory $\mathrm{T}$ cells and expression of FOXP3 in nasal polyp tissue of CRSwNP patients compared with CRSsNP and control subjects $[9,10]$. However, these studies did not clarify the reason for the impaired recruitment of these cells and the decreased expression of FOXP3 in the nasal polyps. A recent study demonstrated that a decreased number of Treg in bronchoalveolar lavage fluid (BALF) correlated with decreased migratory function of Treg in allergic asthma patients [11].

Treg express multiple chemokine receptors, controlling their migration to different organs and tissues [12]. Previous reports have shown that Treg express high levels of CCR4 and CCR8 and functionally respond to CCL17/CCL22 and CCL1, respectively [13,14]. In allergic asthma, Treg showed decreased chemotactic responses, specifically to CCL1, in comparison with healthy controls [15]. Moreover, CCL1 was localized predominantly to the airway epithelium and may play a role in lymphocyte recruitment in bronchial asthma [16]. These studies indicated that several chemokines that are produced by airway epithelial cells can allow Treg to migrate into the tissue. Our preliminary data showed that airway epithelial cells produce chemokines for helper T cells, such as TSLP, in the basal state (data not shown).

In this study, we hypothesized that recruitment of Treg and expression of FOXP3 may be decreased in the nasal polyps of CRSwNP subjects, and that these are associated with impaired migratory function of Treg in CRSwNP subjects. We investigated whether Treg from patients with CRSwNP migrated to bronchial epithelial cells (BECs) and primary nasal epithelial cells (PNECs) to a lesser degree than Treg from patients with CRSsNP or healthy controls. Furthermore, we compared the absolute numbers and phenotype of Treg in the circulation between the 3 groups. Our data suggest that the migratory potentials of Treg toward airway epithelial cells were lower in CRSwNP patients compared with CRSsNP or controls.

\section{Materials and methods}

\section{Patients}

Twenty-four patients with CRSwNP, twenty-two patients with CRSsNP, and eighteen control subjects were included in the study of circulating Treg count. There were 9 asthma and 11 allergic rhinitis (AR) patients in the CRSwNP group, 3 asthma and 5 AR patients in the CRSsNP group, and 3 asthma and 3 AR patients in the control group. Samples from the ethmoid mucosa, nasal septal mucosa, and ethmoidal polyps (if present) were used for immunohistochemistry and QT-PCR, and were collected from eight control subjects, fifteen 
subjects with CRSwNP, and fifteen subjects with CRSsNP. Twelve subjects were included in the migration study for BECs, five for PNECs, and six for chemokines (Table 1).

Ethmoid mucosa or ethmoidal polyp was obtained from CRSwNP and CWSsNP subjects.

Nasal septal mucosa or ethmoid sinus mucosa from patients without sinus disease undergoing endoscopic transsphenoidal resection of pituitary tumor or undergoing septoplasty were collected as controls. About $15 \mathrm{ml}$ of whole blood was drawn at the time of surgery from all the subjects. The diagnosis of sinusitis was based on history, clinical examination, nasal endoscopy, and computed tomography of the paranasal sinuses. Patients were excluded if they had a diagnosis of cystic fibrosis, gross immunodeficiency, congenital mucociliary problems, fungal disease, systemic vasculitis or granulomatous diseases.

Patients with nonallergic rhinitis with and without eosinophilia and vasomotor rhinitis were also excluded. All patients stopped oral and topical application of corticosteroids for at least 1 month before surgery. Patients did not take any other sinonasal medications. Patients who underwent previous sinus surgery were excluded.

An informed consent was obtained from each patient and control subject before collecting material. The study was approved by the Institutional Review Board of the Stanford Medical School.

\section{Immunohistochemistry}

Paraffin-embedded tissue samples were soaked in xylene and then sequentially in solutions of $100 \%, 95 \%$, and $70 \%$ ethanol to remove the paraffin wax. Antigen unmasking was performed by heating the slides in a Decloaking Chamber (Biocare Medical, Concord, CA) to $120^{\circ} \mathrm{C}$ in Diva Decloaking buffer (Biocare Medical, Concord, CA), and then cooled to room temperature. $\mathrm{H}_{2} \mathrm{O}_{2}$ block (Lab Vision, Fremont, $\mathrm{CA}$ ) and protein block (Dako Cytomation, Carpinteria, CA) were then applied to the tissue to prevent non-specific protein binding and to block endogenous peroxidases. Rabbit anti-human CD3 antibody (Vector, Burlingame, CA) was combined with mouse anti-human FOXP3 antibody, (Abcam, Cambridge, MA) was diluted 1:50 with antibody diluent (Dako, Carpinteria, CA) and applied to the tissues for $2 \mathrm{~h}$ at room temperature. After washing, a secondary MACH 2 Universal HRP (Biocare Medical, Concord, CA) antibody was applied for 30 min. After further washing, the slides were stained with DAB (Vector, Burlingame, CA) and Ferangi Blue (BioCare Medical, Concord, CA). FOXP3-positive and CD3-positive (FOXP3 ${ }^{+} \mathrm{CD}^{+}{ }^{+}$) cells and $\mathrm{CD}^{+}$cells were counted per high-powered field $(\mathrm{HPF}, \times 400)$ at three different sites in the tissue and the mean HPF with range was calculated and presented.

\section{QT-PCR}

RNA was isolated using RNeasy kits (Qiagen, Valencia, CA) and according to the manufacturer's protocols. Similar amount of tissues were used for each subject. For cDNA synthesis, $500 \mathrm{ng}$ of total RNA was transcribed with cDNA transcription reagents (Applied Biosystems, Foster City, CA) using random hexamers, according to the manufacturer's protocols. Gene expression was measured in real time using primers and other reagents purchased from Applied Biosystems and SuperArray. All PCR assays were performed in 
triplicate. Data were presented as relative fold expression of the candidate gene to the expression of the housekeeping gene $\beta 2$-microglobulin [17,18].

\section{PBMC separation and regulatory $\mathrm{T}$ cell counts with Flow cytometry}

The peripheral blood mononuclear cells (PBMCs) were separated from the whole blood using Lymphocyte Separation Medium (MP Biomedicals, LLC, Solon, OH). PBMCs were resuspended in Freezing media A (heat-inactivated Fetal Bovine serum), and the same amount of Freezing media B (Fetal Bovine serum and 10\% of DMSO) was added slowly in a drop-wise manner while shaking the tube gently. Then PBMCs were stored in the freezing container (filled with ethanol) and leave in the $-80 \mathrm{C}$ freezer for at least $24 \mathrm{~h}$. After $24 \mathrm{~h}$, PBMCs were transferred to the storage box in the $-80 \mathrm{C}$ freezer until they were used. After storage at $-80 \mathrm{C}$ for 1 day to 6 weeks, the PBMCs were defrosted. The cell viability was found to be greater than $90 \%$, as determined by a trypan blue exclusion assay.

The circulating regulatory $\mathrm{T}$ cells were counted after thawed PBMCs underwent fluorescent antibody staining with CD4-APC (BD Pharminogen, San Diego, CA), CD25-PE (BD Pharminogen, San Diego, CA), CD127-FITC (eBiosciences, San Diego, CA) and Propidium Iodide (BD Pharminogen, San Diego, CA). FACS analysis was used to count $\mathrm{CD} 4+\mathrm{CD} 25^{\text {high }} \mathrm{CD} 127^{\text {low }}$ live cells, which we defined as regulatory $\mathrm{T}$ cells (Fig. 1). Using FlowJo software (version 7.5.2, Ashland, OR) the percent of regulatory $\mathrm{T}$ cells was recorded for each patient sample and results from the three groups were compared.

\section{Cell culture}

Human BECs (PromoCell, Heidelberg, Germany) were purchased and maintained in Airway Epithelial Cell growth medium (Airway Medium-2, PromoCell, Heidelberg, Germany) supplemented with $50 \mathrm{U}-50 \mathrm{mg} / \mathrm{ml}$ of penicillin-streptomycin (Gibco, Carlsbad, CA) in a humidified atmosphere containing $5 \% \mathrm{CO}_{2}$ at $37 \mathrm{C}$. Cells were seeded into 6-well culture plates (BD Biosciences, San Jose, CA) at a density of $5 \times 10^{5}$ cells $/$ well.

For cultivating PNECs, nasal mucosa and nasal polyps were obtained from patients of each group undergoing endoscopic sinus surgery. The tissue samples were washed with Dulbecco's modified Eagle's medium (DMEM/F12) (Invitrogen, Carlsbad, CA) and then incubated with $1 \%$ of pronase (Sigma, type XIV, St. Louis, MO) and $0.01 \%$ of deoxyribonuclease 1 (Sigma, St. Louis, MO) in DMEM/F12 supplemented with 50 U-50 $\mathrm{mg} / \mathrm{ml}$ of penicillin-streptomycin at $4 \mathrm{C}$ for $16-20 \mathrm{~h}$ with rotary agitation $(60 \mathrm{rpm})$. Ten percent fetal calf serum (FCS, Gibco, Carlsbad, CA) was then added to neutralize the enzyme. The cell suspension was filtered using a $100 \mu \mathrm{m}$ nylon cell strainer (BD Biosciences, San Jose, CA) and pre-plated for $2 \mathrm{~h}$ at $37 \mathrm{C}$ on plastic dishes (BD Biosciences, San Jose, CA) to eliminate most of the contaminating fibroblasts. Dissociated cells were counted and resuspended in Airway Medium-1 $1 \%$ of MEM Non-Essential Amino Acids (Gibco, Carlsbad, CA) Solution and $5 \%$ of FCS in DMEM/F12 after centrifugation at $400 g$ for $5 \mathrm{~min}$. The cell suspension (1-1.5 ml) was seeded onto the top of type IV collagen (human placenta collagen, Sigma-Aldrich, $10-20 \mu \mathrm{g} / \mathrm{cm}^{2}$ )-coated polyester membranes (24 mm diameter, pore size $0.4 \mu \mathrm{m}$, Transwell-Clear Costar, Corning, Lowell, MA). The volume of medium under the membrane insert was sufficient $(2-2.6 \mathrm{ml})$ to immerse the membrane 
bottom without floating the insert. Airway Medium-1 on both sides of the membrane was changed to Airway Medium 2 after $24 \mathrm{~h}$. The medium was changed every 2 days. At confluence, an air-liquid interface (ALI) was created by removing the apical medium.

\section{Chemotaxis assay}

The chemotaxis protocol was performed as previously described [15,18-20]. Briefly, after thawing, PBMCs were incubated in a humidified atmosphere containing $5 \% \mathrm{CO}_{2}$ at $37 \mathrm{C}$ for $12-18 \mathrm{~h}$ before doing chemotaxis assay. Specific migration of Treg and non-Treg was evaluated with a $5-\mu \mathrm{m}$ Transwell system (Corning, Lowell, MA). PBMCs $\left(5 \times 10^{5}\right)$ were suspended in $100 \mu \mathrm{L}$ of Airway Medium-2 and added to the top compartment. Six hundred $\mu \mathrm{L}$ of Airway Medium-2 was added to the lower compartment. In case of migration assay with epithelial cells, PNECs or BECs were seeded and grown on the bottom of the lower compartment until they reach $80-90 \%$ of confluence. For the chemotaxis assay with chemokines, $100 \mathrm{nM} / 1$ of CCL1 (Cell Sciences, Canton, MA), $100 \mathrm{nM} / 1$ of CCL17 (Cell Sciences, Canton, MA), and 200 nM/l of CCL22 (GeneWay Biotech, San Diego, CA) were added to the lower compartment. Migration was assayed for $2 \mathrm{~h}$ at $37 \mathrm{C}$, and then the inserts were removed. Migrated Treg and non-Treg were counted with flow cytometry. The number of cells that migrated to the lower compartment in the system with chemokines added (BECs or PNECs with CCL1, CCL17, or CCL22) divided by the number of cells that spontaneously migrated to the lower compartment with medium only were used to calculate the migration indices. Each assay was performed in triplicate.

\section{Statistical analysis}

All statistical procedures were performed with Prism software (GraphPad, Inc, San Diego, CA). Statistical comparisons of data among groups were performed using Mann-Whitney $U$ test. Differences were considered significant at a $P$-value of less than or equal to 0.05 . Correction for multiple comparisons was performed by using the Bonferroni method in the case of the chemotaxis assay of Treg. A detailed description of each statistical test is available in the figure legends.

\section{Results}

\section{Frequencies of Treg in the tissue were lower in subjects with CRSwNP}

Immunohistochemical staining was performed to determine the presence of $\mathrm{FOXP} 3{ }^{+} \mathrm{CD} 3^{+}$ cells in the tissue samples from the three groups. Single tissue sections were double stained with both CD3 and FOXP3. This was the most optimal method at the current time to detect $\mathrm{T}$ cells with a regulatory phenotype in tissues. $\mathrm{FOXP} 3{ }^{+} \mathrm{CD}^{+}$cells were higher in both control subjects (Fig. 2A) and CRSsNP patients (Fig. 2C) compared to CRSwNP patients (Fig. 2B). The average counts for FOXP $3^{+} \mathrm{CD} 3{ }^{+}$cells per high power field (HPF) were significantly lower in CRSwNP patients $(6.16 \pm 2.75$ cells/high power field $)$ compared with controls $(11.33 \pm 9.9)$ and CRSsNP $(20.29 \pm 11.09)$ (Fig. 2D). The number of $\mathrm{CD}^{+}$cells was also counted to estimate the presence of $\mathrm{T}$ cells in the tissue samples from the three groups. The average number of $\mathrm{CD}^{+}$cells was significantly higher in CRSwNP $(58.93 \pm$ 43.18) and CRSsNP (74.71 \pm 49.95$)$ subjects compared with controls (16.16 \pm 8.98$)$ (Fig. 2E). To measure actual Treg function in each group, the proportion of Treg as a fraction of 
total $\mathrm{T}$ cells $\left(\mathrm{CD}^{+}\right.$cells) was calculated. The proportions of Treg to total $\mathrm{T}$ cells were more significantly decreased in CRSwNP subjects compared with CRSsNP ( $p$ value, $<0.01$ vs. $<0.001$ ) (Fig. 2D vs. F). This result indicated that actual functional inhibitory deficiency of Treg can be more aggravated under inflamed circumstances, as seen in nasal polyps.

\section{Expressions of FOXP3 and CCL1 transcript were also lower in subjects with CRSwNP}

The nasal tissue expression of FOXP3, IL-10, TGF- $\beta 1$, CCL1, CCL17, and CCL22 were analyzed by means of RT-PCR in the tissue from three groups. Expression of FOXP3 transcript was also significantly lower in CRSwNP subjects (1.08 \pm 0.26 , relative folds of mRNA) compared with controls (5.89 \pm 0.82$)$ and CRSsNP (3.46 \pm 0.54$)$ subjects (Fig. 3A). Our results indicate that infiltration of Treg and expression of FOXP3 mRNA in the tissues was lower in CRSwNP subjects compared with CRSsNP or control subjects. FOXP3 expression in CRSsNP subjects was significantly lower than that in controls, and we could see this tendency in the ratio of Treg to total T cells between controls and CRSsNP (Fig. $2 \mathrm{~F}$ ), although there was no significant difference between them.

Interestingly, CCL1 expression was significantly upregulated in CRSwNP $(2.2 \pm 1.42)$ compared with controls $(1.17 \pm 0.74)$ and CRSsNP $(1.42 \pm 1.07)$ group (Fig. 3D). However, there were no significant differences in IL-10, TGF- $\beta 1$, CCL17, and CCL22 expression among the three groups (Figs. 3B, C, E and F).

\section{Regulatory $\mathrm{T}$ cell counts in circulating blood}

The percentage of Treg in the PBMCs was determined using flow cytometry because the amount of Treg in the peripheral blood can affect the migration indices in the chemotaxis assay and the infiltration of Treg in tissues. However, there were no significant differences between subjects with CRSwNP and control or CRSsNP subjects (Fig. 4). This indicates that it was unlikely that a systemic defect in Treg number resulted in the decreased recruitment of Treg into the nasal polyp tissue.

The percentage of peripheral Treg was significantly higher in CRSsNP subjects as compared with controls $(p<0.01)$. This result indicates that the chronic and persistent inflammatory state associated with CRSsNP may affect the number of peripheral Treg. There was no significant difference in peripheral Treg percentage between controls and CRSwNP subjects (Fig. 4).

\section{Migration and chemotactic deficiencies are specific to the Treg subset and CCL1 in CRSwNP subjects}

Since the mean percentage of circulating Treg in CRSwNP subjects was not significantly different from those of the controls and CRSsNP subjects, the in vitro migration assays were used to evaluate the migratory potentials of Treg toward BECs and PNECs that originated from the same patients. The chemotactic response of each cell subset to BECs or PNECs was analyzed using the migration indices obtained from the three different groups.

Migration indices of Treg toward BECs were significantly lower in CRSwNP patients (0.85 $\pm 0.20)$ compared with CRSsNP subjects $(1.21 \pm 0.36)$ and controls $(1.24 \pm 0.54)$ (Fig. 5A). 
The migration indices of non-Treg toward BECs were shown to be decreased in CRSwNP subjects although there were no significant differences (Fig. 5B). We calculated the ratio of the migration indices of Treg to non-Treg. The ratio of the migration indices of Treg to nonTreg was also significantly lower in CRSwNP subjects compared to CRSsNP subjects ( $p$ value, $<0.05$ vs. $<0.01$ ) and to controls ( $p$ value, $<0.01$ vs. $<0.005$ ) (Fig. 5A vs. Fig. 5 C). This result indicates that the migration deficiency in CRSwNP subjects is most likely specific to the Treg subset.

Migration potentials toward PNECs were similar to the BECs. The migration indices of Treg toward PNECs were significantly lower in CRSwNP (1.2 \pm 0.14$)$ subjects compared with CRSsNP $(1.51 \pm 0.30)$ and controls $(1.60 \pm 0.56)$ (Fig. 5D). There were no significant differences in migration indices of non-Treg toward both BECs and PNECs among the three groups (Figs. 5B and E). The comparison of migration potential data of Treg toward PNECs vs. Treg toward BECs was not significantly different; therefore, this suggests that there is attenuated migration of Treg to airway epithelium in subjects with CRSwNP.

We next attempted to investigate the migratory potential of each cell type toward several chemokines known to be associated with migration of Treg, such as CCL1, CCL17, and CCL22, because the expression of CCL1 in nasal polyp was significantly upregulated compared with other groups. The chemotactic response of each cell subset to a particular chemokine was also analyzed by using the chemotactic indices. The chemotactic indices of Treg toward CCL1 were significantly lower in CRSwNP $(0.95 \pm 0.16)$ subjects as compared with CRSsNP subjects $(1.37 \pm 0.23)$ or controls $(1.68 \pm 0.68)$ (Fig. 6A). However, there were no significant differences in chemotaxis using CCL17 and CCL22 among the three groups (Fig. 6C and E). In addition, there were no significant differences in migration indices of non-Treg toward CCL1, CCL17, and CCL22 among the three groups (Fig. 6B, D, and F). Although our sample size was small, these results indicated that chemotactic deficiencies are specific to the Treg subset and CCL1.

\section{Discussion}

Our results are in contrast to a previous report, in which both CRSsNP and CRSwNP patients demonstrated impaired regulatory $T$ cell function and enhanced $T_{H} 1 / T_{H} 2 / T_{H} 17$ responses compared to control subjects [21]. Despite the different results, both studies support the hypothesis that a defect in the function of regulatory $\mathrm{T}$ cell system plays an important role in the pathogenesis of CRSwNP.

In a recent study, the number of Treg was lower in the BALF but not in the peripheral blood of asthmatic patients. These results suggest that there is the possibility of defective recruitment of Treg towards the airway mucosa in asthmatic inflammation [11]. Similar to asthmatic patients, our study showed that the infiltration of Treg was decreased in nasal polyp tissues of CRSwNP subjects as compared with control subjects or CRSsNP subjects.

Naturally occurring thymus-derived Treg play a central role in the control of immune responses in autoimmune diseases, allergic disorders, infections, transplantation and cancer $[22,23]$. The number and function of Treg were found to be less in patients with myasthenia 
gravis, systemic lupus erythematosus, rheumatoid arthritis and multiple sclerosis [24]. Patients with atopic dermatitis had more Treg in the peripheral blood than healthy control subjects or asthmatic control subjects [25]. Our results, however, showed that there was no significant difference in the percentage of peripheral Treg between CRSwNP subjects and controls or CRSsNP subjects. This indicated that it was unlikely that a systemic defect in Treg number resulted in the decreased recruitment of Treg into the nasal polyp tissues.

Recent studies demonstrated that airway epithelial cells, including nasal epithelial cells, are able to produce several chemokines that attract immune cells towards the epithelium and into the submucosa [26,27]. Our results show that the PNECs were able to produce the chemokines that are required to attract Treg without any stimulus in their basal state. Our preliminary data show that BECs produced chemokines for helper T cells, such as TSLP, in the basal state (data not shown). PNECs are more physiologic than BECs to observe migration of Treg toward airway epithelial cells; however, it is difficult to cultivate PNECs since there are confounding variables of infection from several pathogens. For this reason we conducted chemotaxis assays in both type epithelial cells. Importantly, when the migration indices of Treg toward the PNECs were compared with those toward the BECs, the studies showed similar results (Fig. 5A and D).

Lymphocyte migration from the peripheral circulation into the tissue is a highly regulated process, determined by tissue-specific signals and receptors, the expression of which are in turn dependent on the release of a precise mixture of chemokines and cytokines [28]. Previous reports have shown that like $\mathrm{T}_{\mathrm{H}}$ 2-biased CD4+ $\mathrm{T}$ cells, Treg express high levels of CCR4 and CCR8 and functionally respond to CCL1 and CCL17/ CCL22 [13,14]. These data suggest that Treg are potentially able to migrate toward these chemokines in severe persistent $\mathrm{T}_{\mathrm{H}}$ 2-skewed airway inflammation, which is often observed in patients with CRSwNP, to suppress hyperactive immune responses [29].

Our data demonstrate that the chemotactic responses of Treg to CCL1 were lower in CRSwNP subjects compared with controls or CRSsNP subjects. These results suggest that the decreased chemotactic response of Treg to CCL1 could possibly lead to the decreased accumulation of Treg in the nasal polyp tissue and subsequent possible ineffective immune regulation by Treg against $\mathrm{T}_{\mathrm{H}} 2$ skewed eosinophilic inflammation in nasal polyps.

Previous reports have shown that the major sources of CCL1 are endothelial cells, mast cells, and LC. The expression of the CCL1 is significantly and selectively up-regulated in atopic dermatitis in comparison to psoriasis, cutaneous lupus erythematosus, or normal skin [30]. In our study, the tissue expression of CCL1 was also significantly up-regulated in CRSwNP subjects as compared with CRSsNP subjects or controls (Fig. 3D). This suggested that the chemotactic response of Treg towards CCL1 in the nasal mucosa is lower in CRSwNP subjects as compared with CRSsNP subjects or controls.

This study also emphasizes that CRS is a heterogeneous disease. Subjects with CRS without polyposis displayed a distinctly different phenotype as compared with subjects with CRSwNP, in that they expressed higher levels of FOXP3 in nasal mucosa and showed higher migration potentials toward airway epithelium and CCL1, similar to control subjects. 
Phenotypic characterization of the subjects with CRSwNP shows that the majority, but not all, of these patients also had asthma (eleven of fifteen, eight of twelve, and four of six subjects, respectively), consistent with previously published studies $[31,32]$.

Two main cell populations have been described for Treg. One is composed of the naturally occurring Treg (nTreg), which is characterized by the $\mathrm{CD} 4{ }^{+} \mathrm{CD} 25^{+} \mathrm{FOXP} 3^{+}$phenotype and matured functionally in the thymus. It is conjectured that nTreg inhibits Th2 and Th1 cells via cell-cell contact [33]. The other group of Treg is composed of the induced Treg (iTreg), which is generated from naïve $\mathrm{T}$ cells in the periphery. The most important subsets of iTreg are $\operatorname{Tr} 1$ and $\operatorname{Th} 3$ cells. They suppress immune function by secretion of predominantly IL-10 and TGF- $\beta 1$, respectively [34]. Recent studies demonstrate that both nTreg and iTreg can induce the FOXP3 transcriptional factors as a marker, and can have complementary and overlapping functions. In our study, we also measured IL-10 and TGF- $\beta 1$ at the mRNA level in the tissues as indirect markers for $\operatorname{Tr} 1$ and $\operatorname{Th} 3$ activity. However, there were no significant differences in IL- 10 and TGF- $\beta 1$ mRNA expression between the three groups (Fig. 3B and C). Numerous other cell types can also express TGF- $\beta 1$, such as macrophages, mast cells, neutrophils, eosinophils, endothelial and epithelial cells, and fibroblasts [9]. $\mathrm{CD}^{+}{ }^{+}$effector $\mathrm{T}$ cells can be stimulated to produce considerable amounts of IL-10 in vivo [35]. These factors might have affected our results so that the expression of IL-10 and TGF$\beta 1$ was not decreased in CRSwNP subjects despite TGF- $\beta 1$ expression being significantly decreased in the nasal polyp tissues of CRSwNP subjects in other studies $[9,36]$.

In conclusion, our data suggest that there is attenuated migration of Treg in subjects with CRSwNP. This may be one of the reasons why nasal mucosal infiltration of Treg is decreased in CRSwNP. Decreased Treg presence could lead to unchecked cell proliferation and inflammation in CRSwNP.

\section{Acknowledgments}

We thank the patients and their families. We also thank the Immunity, Transplantation and Infectious Disease Institute at Stanford University (Seed Grant, Dr. Nadeau, PI) and thank the Department of Otolaryngology at Stanford University School of Medicine (Dr. Hwang and Dr. Jackler).

\section{References}

1. Otto BA, Wenzel SE. The role of cytokines in chronic rhinosinusitis with nasal polyps. Curr Opin Otolaryngol Head Neck Surg. 2008; 16:270-274. [PubMed: 18475084]

2. Robinson DS. The role of regulatory T lymphocytes in asthma pathogenesis. Curr Allergy Asthma Rep. 2005; 5:136-141. [PubMed: 15683614]

3. Karagiannidis C, Akdis M, Holopainen P, Woolley NJ, Hense G, Ruckert B, Mantel PY, Menz G, Akdis CA, Blaser K, Schmidt-Weber CB. Glucocorticoids upregulate FOXP3 expression and regulatory T cells in asthma. J Allergy Clin Immunol. 2004; 114:1425-1433. [PubMed: 15577848]

4. Verhagen J, Akdis M, Traidl-Hoffmann C, Schmid-Grendelmeier P, Hijnen D, Knol EF, Behrendt $\mathrm{H}$, Blaser K, Akdis CA. Absence of T-regulatory cell expression and function in atopic dermatitis skin. J Allergy Clin Immunol. 2006; 117:176-183. [PubMed: 16387603]

5. Baecher-Allan C, Viglietta V, Hafler DA. Human CD4+CD25+ regulatory T cells. Semin Immunol. 2004; 16:89-98. [PubMed: 15036232]

6. Umetsu DT, Akbari O, Dekruyff RH. Regulatory T cells control the development of allergic disease and asthma. J Allergy Clin Immunol. 2003; 112:480-487. quiz 488. [PubMed: 13679803] 
7. Fontenot JD, Gavin MA, Rudensky AY. Foxp3 programs the development and function of CD4+CD25+ regulatory T cells. Nat Immunol. 2003; 4:330-336. [PubMed: 12612578]

8. Khattri R, Cox T, Yasayko SA, Ramsdell F. An essential role for Scurfin in CD4+CD25+ T regulatory cells. Nat Immunol. 2003; 4:337-342. [PubMed: 12612581]

9. Van Bruaene N, Perez-Novo CA, Basinski TM, Van Zele T, Holtappels G, De Ruyck N, SchmidtWeber C, Akdis C, Van Cauwenberge P, Bachert C, Gevaert P. T-cell regulation in chronic paranasal sinus disease. J Allergy Clin Immunol. 2008; 121:1435-1441. 1441, e1-3. [PubMed: 18423831]

10. Li HB, Cai KM, Liu Z, Xia JH, Zhang Y, Xu R, Xu G. Foxp3+ T regulatory cells (Tregs) are increased in nasal polyps (NP) after treatment with intranasal steroid. Clin Immunol. 2008; 129:394-400. [PubMed: 18793874]

11. Hartl D, Koller B, Mehlhorn AT, Reinhardt D, Nicolai T, Schendel DJ, Griese M, KraussEtschmann S. Quantitative and functional impairment of pulmonary CD4+CD25hi regulatory T cells in pediatric asthma. J Allergy Clin Immunol. 2007; 119:1258-1266. [PubMed: 17412402]

12. Wei S, Kryczek I, Zou W. Regulatory T-cell compartmentalization and trafficking. Blood. 2006; 108:426-431. [PubMed: 16537800]

13. Iellem A, Mariani M, Lang R, Recalde H, Panina-Bordignon P, Sinigaglia F, D'Ambrosio D. Unique chemotactic response profile and specific expression of chemokine receptors CCR4 and CCR8 by CD4(+)CD25(+) regulatory T cells. J Exp Med. 2001; 194:847-853. [PubMed: 11560999]

14. Soler D, Chapman TR, Poisson LR, Wang L, Cote-Sierra J, Ryan M, McDonald A, Badola S, Fedyk E, Coyle AJ, Hodge MR, Kolbeck R. CCR8 expression identifies CD4 memory T cells enriched for FOXP3+ regulatory and Th2 effector lymphocytes. J Immunol. 2006; 177:69406951. [PubMed: 17082609]

15. Nguyen KD, Vanichsarn C, Fohner A, Nadeau KC. Selective deregulation in chemokine signaling pathways of CD4+CD25(hi)CD127(lo)/(-) regulatory T cells in human allergic asthma. J Allergy Clin Immunol. 2009; 123:933-939. e10. [PubMed: 19152963]

16. Montes-Vizuet R, Vega-Miranda A, Valencia-Maqueda E, Negrete-Garcia MC, Velasquez JR, Teran LM. CC chemokine ligand 1 is released into the airways of atopic asthmatics. Eur Respir J. 2006; 28:59-67. [PubMed: 16540498]

17. Chong BF, Wilson AJ, Gibson HM, Hafner MS, Luo Y, Hedgcock CJ, Wong HK. Immune function abnormalities in peripheral blood mononuclear cell cytokine expression differentiates stages of cutaneous T-cell lymphoma/mycosis fungoides. Clin Cancer Res. 2008; 14:646-653. [PubMed: 18245523]

18. Nguyen KD, Fohner A, Booker JD, Dong C, Krensky AM, Nadeau KC. XCL1 enhances regulatory activities of CD4+ CD25 (high) CD127(low/-) T cells in human allergic asthma. J Immunol. 2008; 181:5386-5395. [PubMed: 18832695]

19. Yu GP, Chiang D, Song SJ, Hoyte EG, Huang J, Vanishsarn C, Nadeau KC. Regulatory T cell dysfunction in subjects with common variable immunodeficiency complicated by autoimmune disease. Clin Immunol. 2009; 131:240-253. [PubMed: 19162554]

20. Cohen AC, Nadeau KC, Tu W, Hwa V, Dionis K, Bezrodnik L, Teper A, Gaillard M, Heinrich J, Krensky AM, Rosenfeld RG, Lewis DB. Cutting edge: decreased accumulation and regulatory function of CD4+ CD25(high) T cells in human STAT5b deficiency. J Immunol. 2006; 177:2770 2774. [PubMed: 16920911]

21. Cao PP, Li HB, Wang BF, Wang SB, You XJ, Cui YH, Wang DY, Desrosiers M, Liu Z. Distinct immunopathologic characteristics of various types of chronic rhinosinusitis in adult Chinese. $\mathrm{J}$ Allergy Clin Immunol. 2009; 124:478-484. 484, e1-2. [PubMed: 19541359]

22. Sakaguchi S. Regulatory T cells: key controllers of immunologic self-tolerance. Cell. 2000; 101:455-458. [PubMed: 10850488]

23. Hori S, Nomura T, Sakaguchi S. Control of regulatory T cell development by the transcription factor Foxp3. Science. 2003; 299:1057-1061. [PubMed: 12522256]

24. Ozdemir C, Akdis M, Akdis CA. T regulatory cells and their counterparts: masters of immune regulation. Clin Exp Allergy. 2009; 39:626-639. [PubMed: 19422105] 
25. Li LB, Goleva E, Hall CF, Ou LS, Leung DY. Superantigen-induced corticosteroid resistance of human $\mathrm{T}$ cells occurs through activation of the mitogen-activated protein kinase kinase/ extracellular signal-regulated kinase (MEK-ERK) pathway. J Allergy Clin Immunol. 2004; 114:1059-1069. [PubMed: 15536411]

26. Caversaccio M, Hartnell A, Calnan D, Jose P, Mackay IS, Uguccioni M, Baggiolini M, Williams TJ, Conroy DM. The role of chemokines in nasal polyps. Schweiz Med Wochenschr Suppl. 2000; 125:92S-95S.

27. Ying S, O'Connor B, Ratoff J, Meng Q, Fang C, Cousins D, Zhang G, Gu S, Gao Z, Shamji B, Edwards MJ, Lee TH, Corrigan CJ. Expression and cellular provenance of thymic stromal lymphopoietin and chemokines in patients with severe asthma and chronic obstructive pulmonary disease. J Immunol. 2008; 181:2790-2798. [PubMed: 18684970]

28. Kruger K, Mooren FC. T cell homing and exercise. Exerc Immunol Rev. 2007; 13:37-54. [PubMed: 18198659]

29. Sather BD, Treuting P, Perdue N, Miazgowicz M, Fontenot JD, Rudensky AY, Campbell DJ. Altering the distribution of Foxp3(+) regulatory T cells results in tissue-specific inflammatory disease. J Exp Med. 2007; 204:1335-1347. [PubMed: 17548521]

30. Gombert M, Dieu-Nosjean MC, Winterberg F, Bunemann E, Kubitza RC, Da Cunha L, Haahtela A, Lehtimaki S, Muller A, Rieker J, Meller S, Pivarcsi A, Koreck A, Fridman WH, Zentgraf HW, Pavenstadt H, Amara A, Caux C, Kemeny L, Alenius H, Lauerma A, Ruzicka T, Zlotnik A, Homey B. CCL1-CCR8 interactions: an axis mediating the recruitment of T cells and Langerhanstype dendritic cells to sites of atopic skin inflammation. J Immunol. 2005; 174:5082-5091. [PubMed: 15814739]

31. Staikuniene J, Vaitkus S, Japertiene LM, Ryskiene S. Association of chronic rhinosinusitis with nasal polyps and asthma: clinical and radiological features, allergy and inflammation markers. Medicina (Kaunas). 2008; 44:257-265. [PubMed: 18469501]

32. Larsen K. The clinical relationship of nasal polyps to asthma. Allergy Asthma Proc. 1996; 17:243249. [PubMed: 8922143]

33. Umetsu DT, DeKruyff RH. The regulation of allergy and asthma. Immunol Rev. 2006; 212:238255. [PubMed: 16903918]

34. Mills KH, McGuirk P. Antigen-specific regulatory T cells-their induction and role in infection. Semin Immunol. 2004; 16:107-117. [PubMed: 15036234]

35. Kearley J, Barker JE, Robinson DS, Lloyd CM. Resolution of airway inflammation and hyperreactivity after in vivo transfer of CD4+CD25+ regulatory T cells is interleukin 10 dependent. J Exp Med. 2005; 202:1539-1547. [PubMed: 16314435]

36. Zhang N, Van Zele T, Perez-Novo C, Van Bruaene N, Holtappels G, DeRuyck N, Van Cauwenberge P, Bachert C. Different types of T-effector cells orchestrate mucosal inflammation in chronic sinus disease. J Allergy Clin Immunol. 2008; 122:961-968. [PubMed: 18804271] 

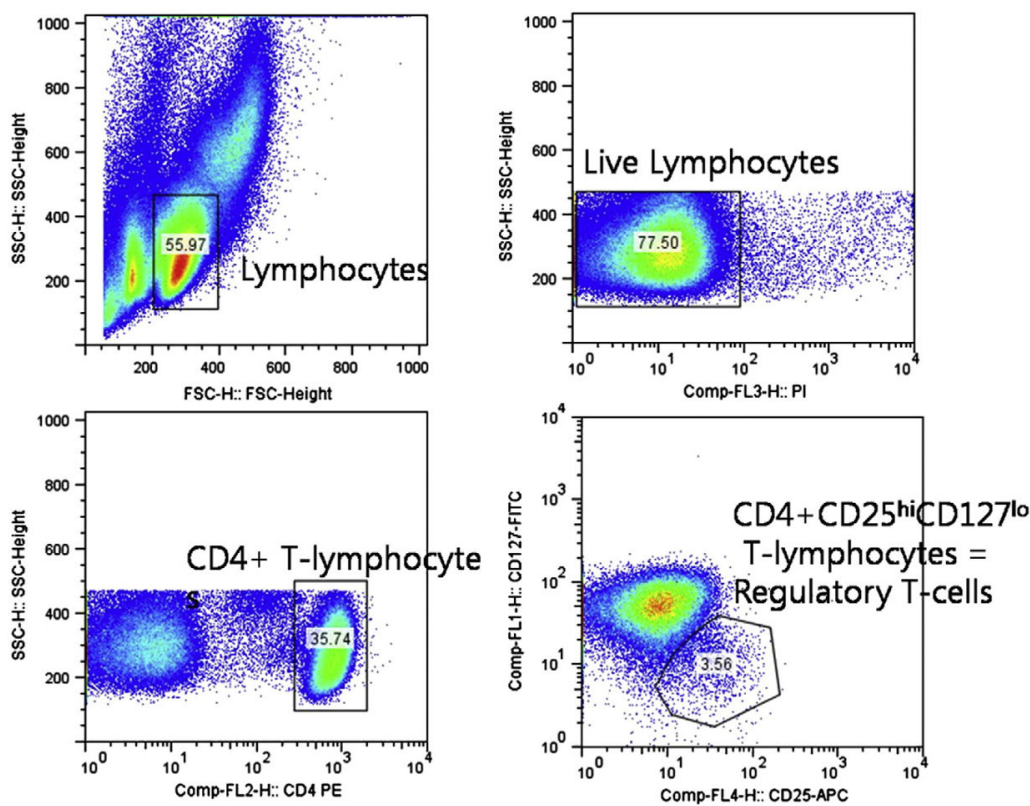

Figure 1.

FACS gating strategy for identifying $\mathrm{CD} 4^{+} \mathrm{CD} 25^{\text {high }} \mathrm{CD} 127^{\text {low }}$ cells. FACS analysis was used to count $\mathrm{CD} 4+\mathrm{CD} 25^{\text {high }} \mathrm{CD} 127^{\text {low }}$ live cells, which we defined as regulatory $\mathrm{T}$ cells. Using FlowJo software, the percent of regulatory $\mathrm{T}$ cells was calculated and recorded for each subject. 
A

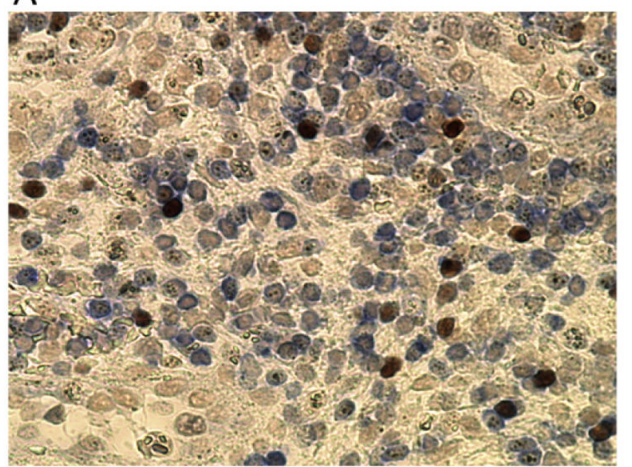

C

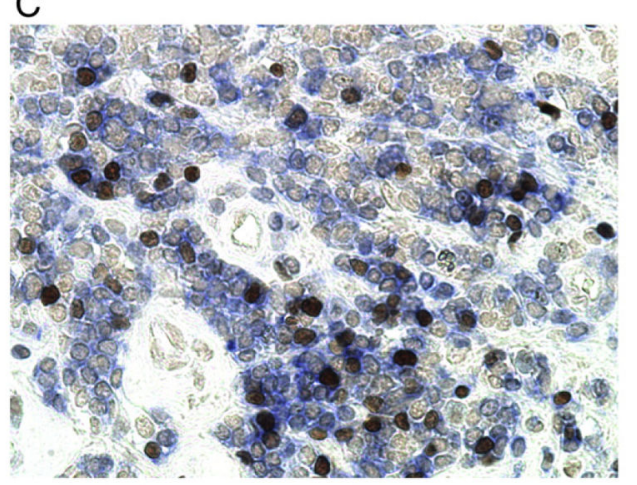

E

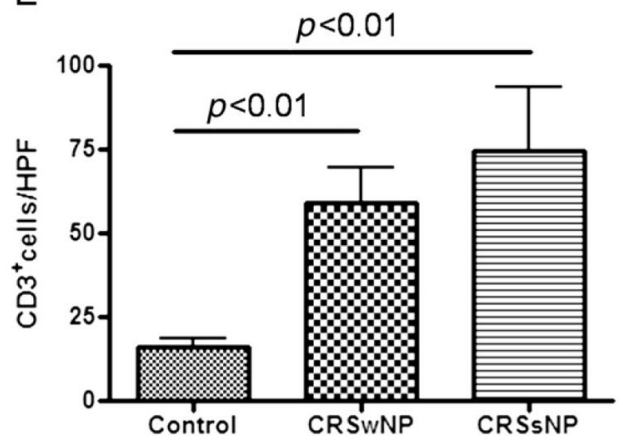

$\mathrm{B}$

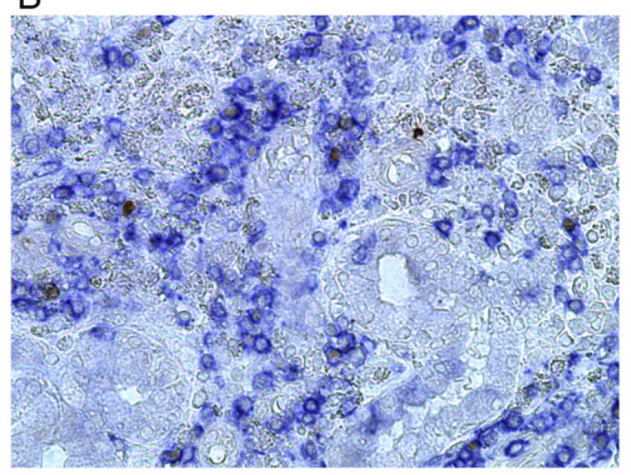

D

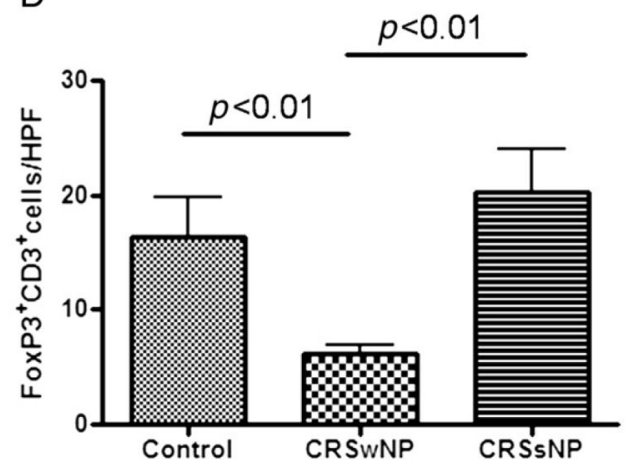

$\mathrm{F}$

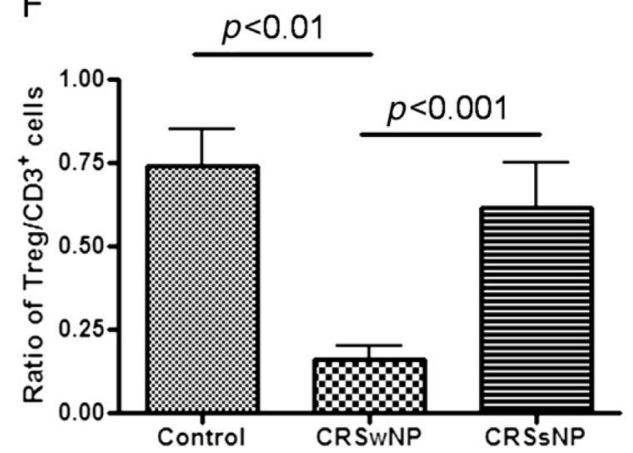

Figure 2.

Expression of $\mathrm{FOXP} 3{ }^{+} \mathrm{CD} 3^{+}$cells in tissue from the three groups. $\mathrm{FOXP} 3{ }^{+} \mathrm{CD} 3^{+}$cells were higher in both control (A) and CRSsNP (C) subjects compared to CRSwNP (B). The average counts for $\mathrm{FOXP} 3^{+} \mathrm{CD} 3^{+}$cells per high power field (HPF) were significantly lower in CRSwNP patients compared with controls and CRSsNP (D). The number of CD3-positive $\left(\mathrm{CD}^{+}\right)$cells was also counted to estimate the presence of T cells in the three groups. The average number of $\mathrm{CD}^{+}$cells was significantly higher in CRSwNP and CRSsNP subjects compared with controls (E). The ratio of Treg to $\mathrm{CD}^{+}$cells is more significantly decreased in CRSwNP compared with controls and CRSsNP subjects (F). 


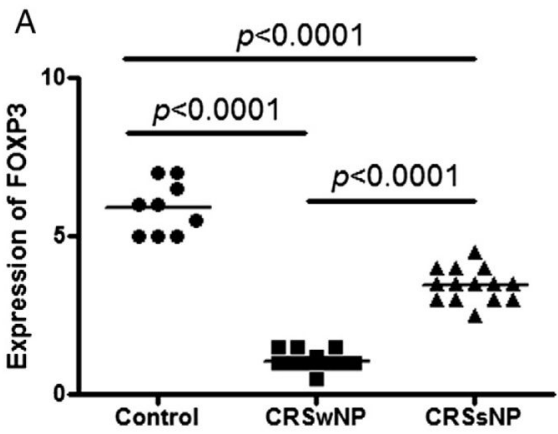

B

C
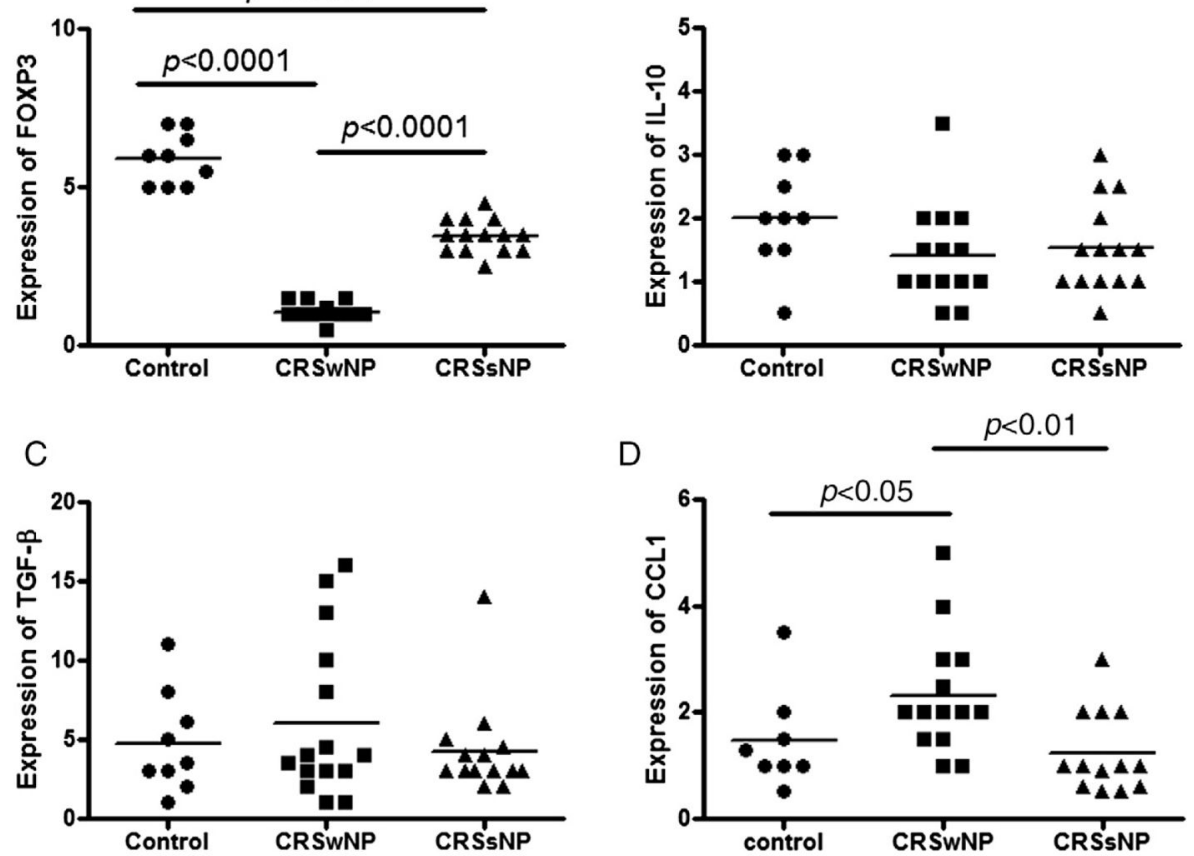

D
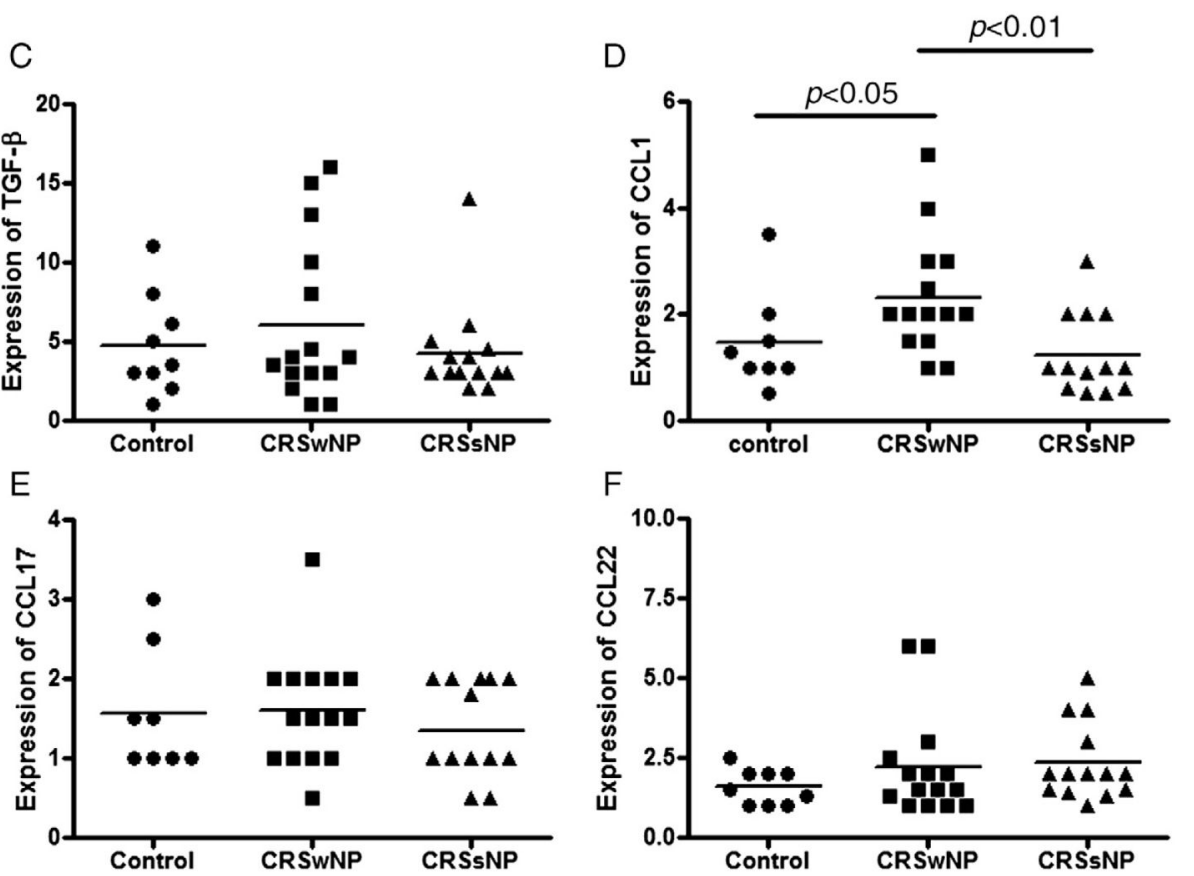

Figure 3.

mRNA expression FOXP3 transcript, IL-10, TGF- $\beta$, and chemokines (CCL1, CCL17, and CCL22). Expression of FOXP3 transcript was significantly lower in nasal polyp tissue of CRSwNP subjects compared with controls and CRSsNP subjects (A) and FOXP3 expression of CRSsNP subjects was significantly lower than that of controls (A). CCL1 expression was significantly upregulated in CRSwNP compared with controls and CRSsNP subjects (D). There were no significant differences in IL-10, TGF- $\beta$, CCL17, and CCL22 expression among the groups (B, C, E and F). 


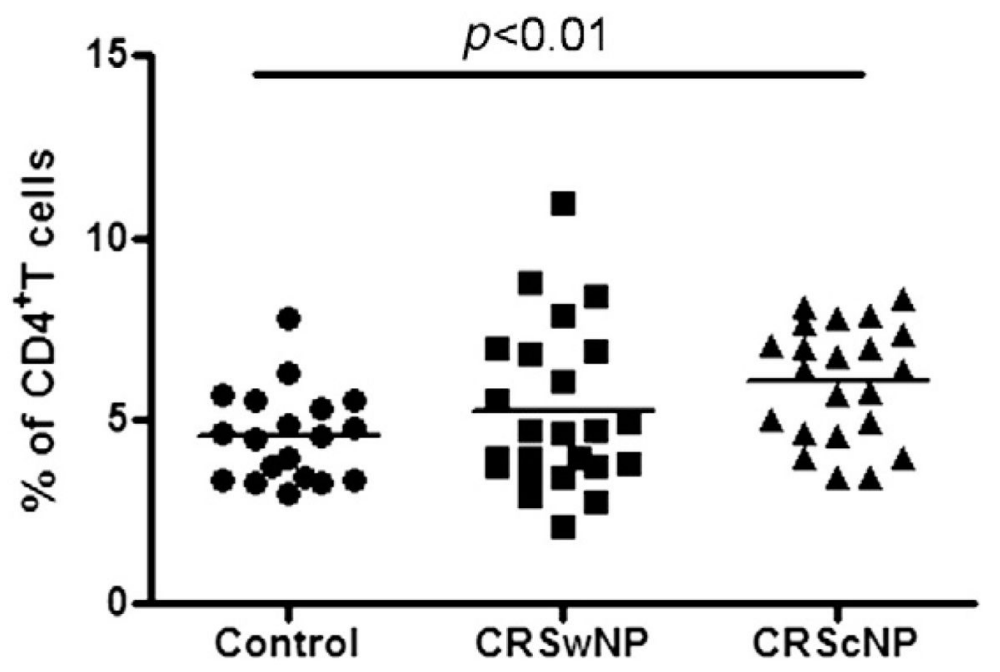

Figure 4.

Regulatory T cells count in peripheral blood. The percentages of Treg in PBMC were counted by using flow cytometry. The percentage of Treg was significantly increased in CRSsNP subjects compared with controls. There were no significant differences between subjects with CRSwNP and control or CRSsNP subjects. 
A

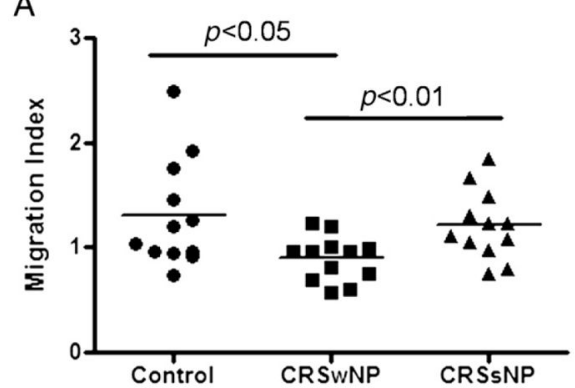

C

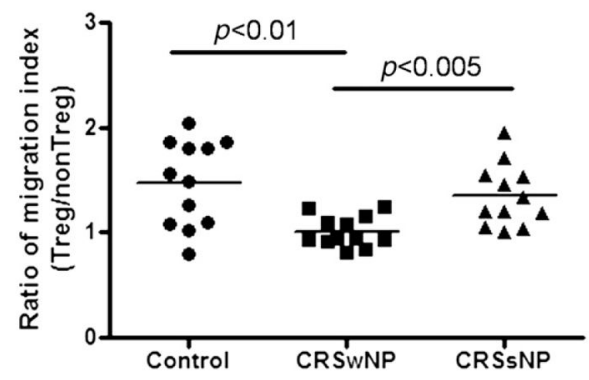

$\mathrm{E}$
B

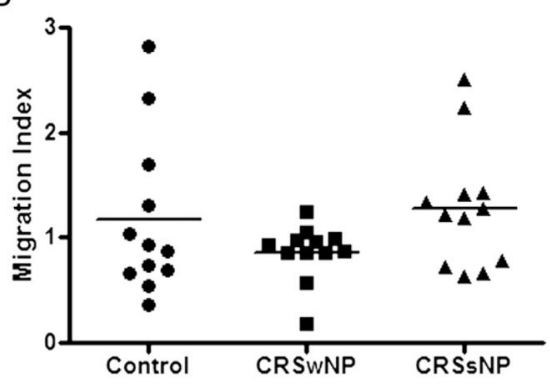

D

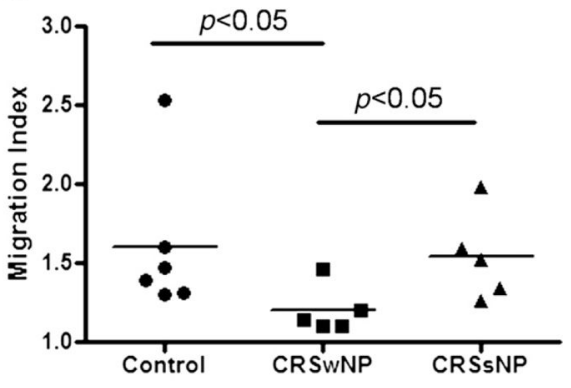

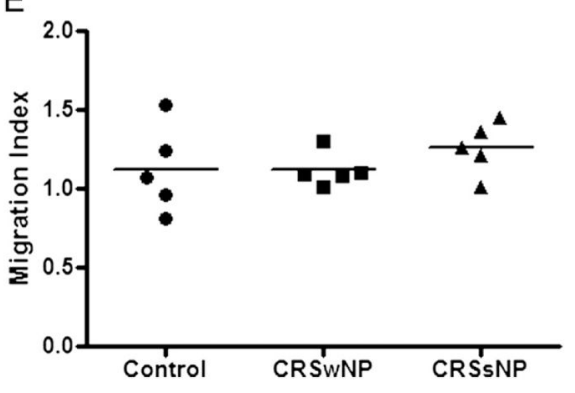

Figure 5.

Chemotactic patterns of Treg (A and D) and non-Treg (B and E) cells toward bronchial epithelial cells (BECs, A, B and C) and primary nasal epithelial cells (PNECs, D and E). Treg: non-Treg migration indices toward BECs using the same sample are shown (C). 
A

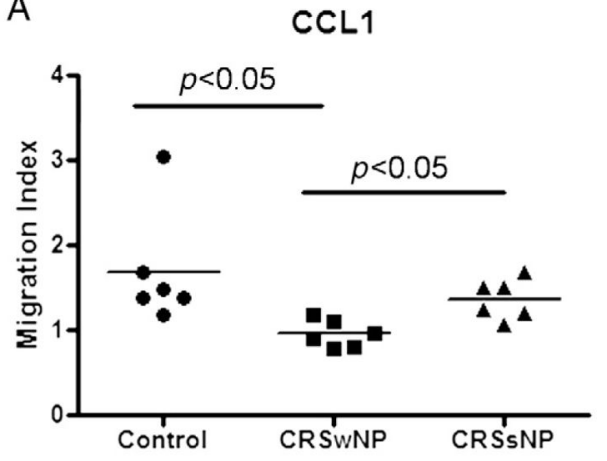

B
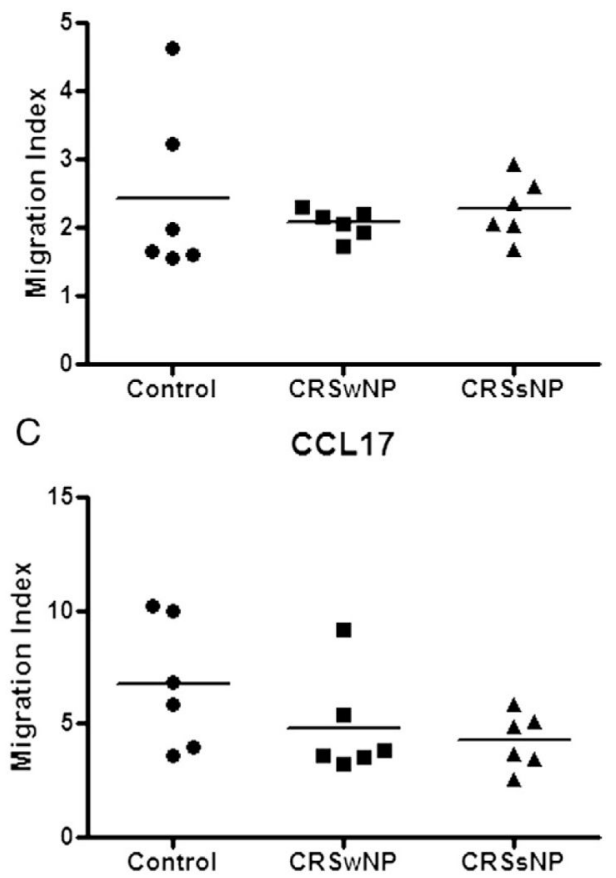

D

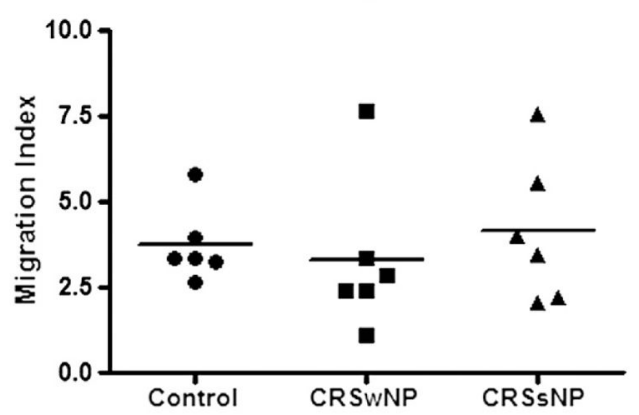

E
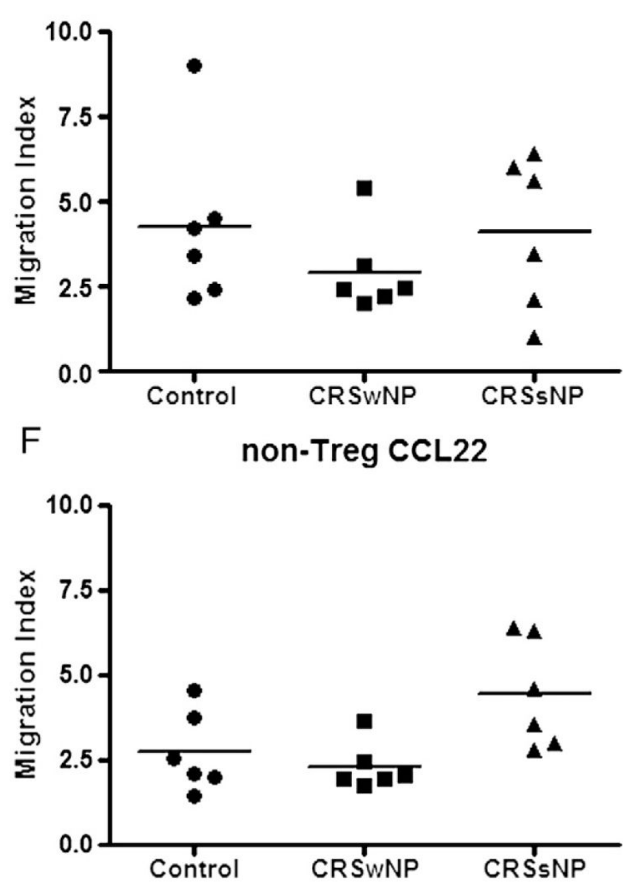

Figure 6.

Specific migration of Treg (A, C, and E) and non-Treg (B, D, and F) cells toward CCL1, CCL17 and CCL22. Correction for multiple comparisons was performed by using the Bonferroni method. 


\section{Table 1}

Patients characteristics.

\begin{tabular}{|c|c|c|c|}
\hline & Number of subject & M:F & Age (mean age) \\
\hline \multicolumn{4}{|c|}{ Circulating Treg Count } \\
\hline Control & $18(4)^{a}$ & $8: 10$ & $23-80(52)$ \\
\hline CRSwNP & $24(19)^{a}$ & $14: 10$ & $25-76(50)$ \\
\hline CRSsNP & $22(7)^{a}$ & $10: 12$ & $28-80(50)$ \\
\hline \multicolumn{4}{|c|}{ IHC stain and RT-PCR } \\
\hline Control & $8(2)^{a}$ & $4: 6$ & $23-80(53)$ \\
\hline CRSwNP & $15(11)^{a}$ & $7: 8$ & $37-73(52)$ \\
\hline CRSsNP & 15 (4) ${ }^{a}$ & $6: 9$ & $29-80(53)$ \\
\hline \multicolumn{4}{|l|}{ Migration Study } \\
\hline \multicolumn{4}{|l|}{ Toward BEC } \\
\hline Control & $12(2)^{a}$ & $5: 7$ & $23-80(52)$ \\
\hline CRSwNP & $12(8)^{a}$ & $6: 6$ & $37-76(52)$ \\
\hline CRSsNP & $12(2)^{a}$ & $7: 5$ & $29-70(51)$ \\
\hline \multicolumn{4}{|c|}{ Toward PNEC } \\
\hline Control & $5(1) \dagger$ & $2: 3$ & $32-47(42.6)$ \\
\hline CRSwNP & $5(4)^{a}$ & $3: 2$ & $25-69(42.8)$ \\
\hline CRSsNP & $5(0)^{a}$ & $2: 3$ & $20-62(40)$ \\
\hline \multicolumn{4}{|c|}{ Toward Chemokines } \\
\hline Control & $6(0)^{a}$ & $3: 3$ & $32-47(43)$ \\
\hline CRSwNP & $6(4)^{a}$ & $3: 3$ & $25-69(44)$ \\
\hline CRSsNP & $6(2)^{a}$ & $3: 3$ & $20-62(44.2)$ \\
\hline
\end{tabular}

IHC, immunohistochemical; BECs, bronchial epithelial cells;PNECs, primary nasal epithelial cells; CRSwNP, chronicrhinosinusitis with nasal polyposis; CRSsNP, chronic rhinosinusitis without nasal polyposis.

${ }^{a}$ Number of patients with allergic diseases. 